\title{
Effect of BRAF mutational status on expression profiles in conventional papillary thyroid carcinomas
}

\author{
Hans-Juergen Schulten ${ }^{1,2^{*}}$, Reem Alotibi ${ }^{1,3}$, Alaa Al-Ahmadi ${ }^{1,3}$, Manar Ata', Sajjad Karim ${ }^{1,2}$, Etimad Huwait ${ }^{3}$, \\ Mamdooh Gari ${ }^{1,2}$, Khalid Al-Ghamdi', Faisal Al-Mashat ${ }^{4}$, Osman Abdel Al-Hamour ${ }^{5}$, \\ Mohammad Hussain Al-Qahtani ${ }^{1,2}$, Jaudah Al-Maghrabi ${ }^{6,7}$
}

From 2nd International Genomic Medicine Conference (IGMC 2013)

Jeddah, Kingdom of Saudi Arabia. 24-27 November 2013

\begin{abstract}
Background: Whereas $40 \%$ to $70 \%$ of papillary thyroid carcinomas (PTCs) are characterized by a BRAF mutation (BRAF ${ }^{\mathrm{mut}}$ ), unified biomarkers for the genetically heterogeneous group of BRAF wild type (BRAF ${ }^{\mathrm{wt}}$ ) PTCs are not established yet. Using state-of-the-art technology we compared RNA expression profiles between conventional $B R A F^{\text {wt }}$ and BRAF ${ }^{\text {mut }}$ PTCs.

Methods: Microarrays covering 36,079 reference sequences were used to generate whole transcript expression profiles in 11 BRAF ${ }^{\text {wt }}$ PTCs including five micro PTCs, 14 BRAF ${ }^{\text {mut }}$ PTCs, and 7 normal thyroid specimens. A $p$-value with a false discovery rate (FDR) $<0.05$ and a fold change $>2$ were used as a threshold of significance for differential expression. Network and pathway utilities were employed to interpret significance of expression data. BRAF mutational status was established by direct sequencing the hotspot region of exon 15 .

Results: We identified 237 annotated genes that were significantly differentially expressed between $B R A F^{w t}$ and $B R A F^{\text {mut }}$ PTCs. Of these, 110 genes were down- and 127 were upregulated in BRAF $F^{\text {wt }}$ compared to BRAF $F^{\text {mut }}$ PTCs. A number of molecules involved in thyroid hormone metabolism including thyroid peroxidase (TPO) were differentially expressed between both groups. Among cancer-associated molecules were ERBB3 that was downregulated and ERBB4 that was upregulated in BRAF ${ }^{\text {wt }}$ PTCs. Two microRNAs were significantly differentially expressed of which miR492 bears predicted functions relevant to thyroid-specific molecules. The protein kinase A (PKA) and the G protein-coupled receptor pathways were identified as significantly related signaling cascades to the gene set of 237 genes. Furthermore, a network of interacting molecules was predicted on basis of the differentially expressed gene set.

Conclusions: The expression study focusing on affected genes that are differentially expressed between BRAFwt and $B R A F^{\text {mut }}$ conventional PTCs identified a number of molecules which are connected in a network and affect important canonical pathways. The identified gene set adds to our understanding of the tumor biology of BRAF ${ }^{\text {wt }}$ and $B R A F^{\text {mut }}$ PTCs and contains genes/biomarkers of interest.
\end{abstract}

\footnotetext{
* Correspondence: hschulten@kau.edu.sa

${ }^{1}$ Center of Excellence in Genomic Medicine Research, King Abdulaziz

University, Jeddah, Saudi Arabia

Full list of author information is available at the end of the article
}

(c) 2015 Schulten et al; licensee BioMed Central Ltd. This is an Open Access article distributed under the terms of the Creative Commons Attribution License (http://creativecommons.org/licenses/by/4.0), which permits unrestricted use, distribution, and reproduction in any medium, provided the original work is properly cited. The Creative Commons Public Domain Dedication waiver Biomed Central (http://creativecommons.org/publicdomain/zero/1.0/) applies to the data made available in this article, unless otherwise stated. 


\section{Background}

Over the last decades the incidence rate of thyroid cancer increases worldwide [1]. In Saudi Arabia, thyroid carcinoma (TC) is considered the second most common cancer in young women [2]. About $80 \%$ of all TCs are PTCs. The majority of PTCs are histologically classified as conventional PTCs. The follicular variant of PTC (FVPTC) represents the largest subtype and accounts for about $30 \%$ of all PTCs [3]. Minor and rare subtypes include Hurthle cell variant PTC and insular PTC which bears an aggressive clinical behavior [4]. Conventional PTCs are characterized on the molecular level by a moderate to high frequency of $B R A F$ mutations $(40 \%-70 \%)$ that distinguishes them from FVPTCs $(10 \%-20 \%)$ [5].

BRAF is a cytoplasmic receptor serine/threonine kinase and a key molecule in the mitogen activated protein kinase (MAPK) pathway. BRAF is mutated in diverse human malignancies although frequency and clinical presentation varies considerably between different types of cancers [6]. Over $90 \%$ of all $B R A F$ mutations are a valine by glycine substitution at codon 600 (V600E) in exon 15 . Other $B R A F$ mutations affect commonly codons adjunct to codon 600. Although the impact of $B R A F$ mutations in PTC is controversially discussed, many studies found an association of $B R A F^{\text {mut }}$ PTCs with unfavorable clinical features including larger tumor size, advanced tumor stage, vessel invasion, capsular invasion, tumor extension, higher risk for lymph node (LN) involvement, distant metastasis, and poor prognosis [7-10]. Consistent with this, patients with a $B R A F^{\text {mut }}$ PTC are considerably older than those with a $B R A F^{\mathrm{wt}}$ PTC $[5,10]$. Whereas a $B R A F$ mutation represents are valuable target for molecular therapy in advanced solid tumors including PTCs, molecular profiles of $B R A F^{\mathrm{wt}}$ PTCs are less known and genetic screening for valuable target genes is primarily limited to research studies [11]. The major deregulated key genes in the $B R A F^{\text {wt }}$ group are $R E T$ and RAS. RAS consists of the highly related genes for HRAS, KRAS, and NRAS. Within the MAPK pathway the RAS molecules transmit signals to the downstream target BRAF. The most common $R E T / \mathrm{PTC}$ fusions are paracentric fusions with the gene entitled coiled-coil domain containing 6 (CCDC6) contributing to $\sim 80 \%$ and with the nuclear receptor coactivator 4 (NCOA4) contributing to $\sim 10 \%$ of all known RET/PTC rearrangements. The frequency of RAS mutations and RET/PTC rearrangements differs between the populations studied and depends in part on the inclusion/exclusion criteria for the different histological PTC subtypes [12]. RAS mutations and RET rearrangements are unlikely to act as molecular drivers for onset of malignancy as they are already present in benign thyroid neoplasms [13,14]. This distinguishes them from BRAF mutations which are virtually absent in precursor lesions of PTCs.
Until now only a few studies compared expression profiles between $B R A F^{\mathrm{wt}}$ and $B R A F^{\mathrm{mut}}$ PTCs using array technologies [15-18]. The relevance of expressional screening in PTC according to their BRAF mutational status is in part related to the different clinical behavior of both PTC groups with the necessity to identify appropriate biomarkers and in part related to the different tumor biology of both groups which is not thoroughly understood [7]. In our study we took advantage of current state-of-the-art technology to screen and analyze a case series of $B R A F^{\mathrm{wt}}$ and $B R A F^{\mathrm{mut}}$ PTCs for detecting new biomarkers which could become useful to distinguish both groups on the molecular level. We did not include FVPTCs and other smaller histological subtypes of PTC in our screening to minimize expressional bias which might be related to a different histology.

\section{Methods \\ Thyroid samples}

We examined 25 specimens from PTCs and seven normal thyroid samples (TN) from patients who were treated surgically in the period between November 2008 and February 2013 at the King Abdulaziz University Hospital, Jeddah, and the King Faisal Specialist Hospital \& Research Center (KFSH\&RC), Jeddah. In two $B R A F^{\text {mut }}$ PTCs, specimens were derived from a recurrence or a local metastasis and in one $B R A F^{\mathrm{wt}}$ PTC from an LN metastasis. Normal thyroid specimens were derived from histopathologically unaffected normal thyroid tissue in the course of lobo- or thyroidetomies of thyroid lesions (4 goiters, 1 hyperthyroiditis, 1 PTC, and 1 FVPTC). Histopathological diagnosis and staging of thyroid lesions was performed by an experienced oncologic pathologist (JM) according to established criteria $[19,20]$. Five $B R A F^{\mathrm{wt}}$ PTCs were classified as micro PTCs $(\leq 1 \mathrm{~cm})$. This study was approved by the Research Ethics Committee of the King Abdulaziz University, Faculty of Medicine, \#358-10, and the Institutional Review Board of the KFSH\&RC, \#IRB2010-07, and included written informed consent provided by the participants.

\section{DNA extraction and BRAF mutational screening}

Genomic DNA from fresh-frozen samples was extracted using the QIAmp DNA tissue kit (Qiagen, Hilden, Germany). DNA concentration was measured with the Nanodrop ND-1000 spectrophotometer (Thermo Scientific, Wilmington, DE). Screening of the BRAF mutational hotspot region of exon 15 was performed as described earlier involving direct sequencing of PCR products spanning the region [5].

\section{RNA sample and array processing}

Total RNA was extracted from freshly preserved thyroid tissue specimens using the Qiagen RNeasy Mini Kit 
(Qiagen, Hilden, Germany) including an on-column DNAse treatment according to manufacturer's recommendations. Quality of the purified RNA was verified on an Agilent 2100 Bioanalyzer (Agilent Technologies, Palo Alto, CA). RNA integrity number for all evaluated samples was at least 5.0. RNA concentrations were determined using a NanoDrop ND-1000 spectrophotometer. Samples containing each $250 \mathrm{ng}$ of RNA were processed using the Ambion WT Expression Kit (Life Technologies, Austin, TX) and the GeneChip WT Terminal Labeling and Controls Kit (Affymetrix, Santa Clara, CA) according to the manufacturers' recommendations. Fragmentation and endlabeling of samples were monitored by electrophoresis on $3 \%$ agarose gels. Affymetrix GeneChip hybridization, wash and stain kits were utilized in subsequent processing steps. Hybridization mixtures containing each $5500 \mathrm{ng}$ of cDNA were hybridized at $45^{\circ} \mathrm{C}$ for $17 \mathrm{hrs}$ and $60 \mathrm{rpm}$ to Affymetrix Human Gene 1.0 ST GeneChip arrays. Subsequent to wash and staining at the GeneChip Fluidics Station 450, the arrays were scanned with the GeneChip Scanner 3000 7G. Probe cell intensity data (CEL files) were generated using the GeneChip Command Console Software (AGCC). Human Gene 1.0 ST GeneChip arrays interrogate in total with a set of 764,885 probes 36.079 reference sequences (NCBI build 36).

\section{Gene Expression Analysis}

CEL files were imported to Partek Genomics Suite version 6.6 (Partek Inc., MO) and a log-transformed data set of robust multi-array averaged (RMA), background-adjusted, and normalized values was generated. Non-annotated genes and multiple transcripts generated from the same gene were excluded from further analysis. Principal component analysis (PCA) was performed to assess quality as well as overall variance in gene expression between groups of samples. Analysis of Variance (ANOVA) was applied to generate a list of differentially expressed genes using a $p$-value with a false discovery rate (FDR) (Step up method) $<0.05$ and a fold change $>2.0$. Two dimensional average linkage hierarchical clustering was performed using Spearman's correlation as a similarity matrix. The generated array data set complies with MIAME [21] and was submitted to NCBI's Gene Expression Omnibus (GEO), accession number GSE54958.

\section{Functional network and pathway analysis}

To define molecular networks and canonical pathways in differentially regulated gene sets, pathway analyses were performed by using Ingenuity Pathways Analysis (IPA) software (Ingenuity Systems, Redwood City, CA). For this purpose, statistically differentially expressed genes and their corresponding probe set ID, gene symbol as clone identifier, $p$-value and fold change were imported into IPA. The program identifies with its functional algorithms those biological functions, interacting drugs and/or diseases that are most significantly related to a differentially expressed gene set. The canonical pathway analysis identifies pathways that are most significantly related to the data set.

\section{Results}

Demographic data of patients and histopathological criteria of $B R A F^{\mathrm{wt}}$ and $B R A F^{\mathrm{mut}}$ PTC are listed in Table 1. A gender shift towards females was observed in the $B R A F^{\mathrm{wt}}$ group and mean age was considerable lower in the $B R A F^{\mathrm{wt}}$ than in the $B R A F^{\mathrm{mut}}$ group (30.9 years $v s$. 45.9 years). Histopathological criteria including tumor size, LN involvement, tumor focality and tumor stage were comparably more unfavorable in $B R A F^{\text {mut }}$ PTCs (Table 1).

\section{Expression $B R A F^{\mathrm{wt}} v s . B R A F^{\mathrm{mut}}$ PTCs}

Employing whole-transcript microarrays (HuGene 1.0 $\mathrm{ST}$ ) we compared expression profiles of $11 B R A F^{\mathrm{wt}}$ PTCs with $14 B R A F^{\text {mut }}$ PTCs. Seven TN specimens were used as a reference for normal thyroid tissue expression which allowed us to identify differentially expressed genes between both PTC groups and TN samples. Three-D presentation of the PCA displays

Table 1 Demographic and clinicopathological features of $B R A F^{\mathrm{wt}}$ and $B R A F^{\mathrm{mut}}$ PTCs

\begin{tabular}{|c|c|c|}
\hline \multirow{2}{*}{$\begin{array}{c}\text { Characteristics } \\
\text { Patient }\end{array}$} & \multicolumn{2}{|c|}{ PTCs } \\
\hline & $B R A F^{\mathrm{wt}}(\mathrm{N}=11)$ & $B R A F^{\text {mut }}(N=14)$ \\
\hline \multicolumn{3}{|l|}{ age (year) } \\
\hline Mean \pm SD & $30.9 \pm 12.2$ & $45.9 \pm 16.4$ \\
\hline$\ddot{\mathrm{E}}, 45$ & 9 & 7 \\
\hline$\geq 45$ & 2 & 7 \\
\hline female & 9 & 9 \\
\hline male & 2 & 5 \\
\hline \multicolumn{3}{|l|}{ Tumor } \\
\hline size $\pm \mathrm{SD}(\mathrm{cm})$ & $2.4 \pm 1.8$ & $4.4 \pm 2.8$ \\
\hline focal & 6 & 3 \\
\hline multifocal & 5 & 11 \\
\hline \multicolumn{3}{|l|}{ lymph node } \\
\hline negative & 5 & 3 \\
\hline positive & 6 & 9 \\
\hline unknown & 0 & 2 \\
\hline \multicolumn{3}{|l|}{ stage } \\
\hline 1 & 10 & 8 \\
\hline$\|$ & 0 & 1 \\
\hline III & 0 & 1 \\
\hline IV & 1 & 3 \\
\hline unknown & 0 & 1 \\
\hline
\end{tabular}


clustering of $B R A F^{\mathrm{wt}}$ PTCs, $B R A F^{\mathrm{mut}}$ PTCs and TN samples (Figure 1). We identified, after excluding nonannotated genes and multiple transcriptional isoforms, 237 annotated genes that were significantly differentially expressed ( $\mathrm{p}$-value with FDR $<0.05$ and a fold change $>2$ ) between $B R A F^{\mathrm{wt}}$ and $B R A F^{\mathrm{mut}}$ PTCs (Additional file 1). Of these genes, 127 were up-, and 110 were downregulated in $B R A F^{\mathrm{wt}}$ compared to $B R A F^{\mathrm{mut}}$ PTCs. The most significantly upregulated genes in $B R A F^{\mathrm{wt}}$ were inositol 1,4,5-triphosphate receptor, type 1 (ITPR1), hepatic leukemia factor (HLF), potassium voltage-gated channel, shaker-related subfamily, beta member 1 (KCNAB1), engulfment and cell motility 1 (ELMO1), Rho GTPase activating protein 24 (ARHGAP24), thyroid peroxidase (TPO) and solute carrier family 4, sodium bicarbonate cotransporter, member 4 (SLC4A4). The most significantly downregulated genes in $B R A F^{\mathrm{wt}}$ PTCs were dendrocyte expressed seven transmembrane protein (DCSTAMP), ladinin 1 (LAD1), keratin 19 (KRT19), chromosome 19 open reading frame 33 (C19orf33), poliovirus receptor-related 4 (PVRL4), EPH receptor A10 (EPHA10), and TBC1 domain family, member 2 (TBC1D2). The list of 237 genes contained one microRNA (MIR492) that was downregulated and one microRNA (MIR32) that was upregulated in $B R A F^{\mathrm{wt}} v s$. $B R A F^{\text {mut }}$ PTCs. Additional file 1 contains also the cellular/extracellular location, function of gene products as well as a selection of drugs known to interact with a gene product. Hierarchical cluster analysis of the 237 genes separates both PTC groups according to their differential gene expression (Figure 2). TN samples were included in this data set to provide normal expression values.

\section{Expression PTCs vs. TN samples}

Comparison of genes differentially expressed between $B R A F^{\mathrm{wt}}$ and TN samples revealed a set of 8249 genes and between $B R A F^{\text {mut }}$ and TN samples a set of 8836 genes. To identify genes of interests, e.g. conceivable immunohistochemistry markers, we selected those genes which are differentially expressed between all three groups (Table 2). In sum, 32 genes met the statistical criteria and the vast majority revealed the comparatively highest expression in $B R A F^{\text {mut }}$ PTCs.

\section{Gene networks and canonical pathways}

Most significant network functions identified by IPA algorithms and associated with the set of 237 differentially expressed genes were involved in cell signaling, cancer, and cellular development (Figure 3). This comprehensive network includes 12 molecules which are overexpressed and 16 molecules which are underexpressed in $B R A F^{\mathrm{wt}}$ compared to $B R A F^{\mathrm{mut}}$ PTCs. The most significantly associated canonical pathway related to the differentially expressed set of 237 genes is the proteinkinase A (PKA) signaling cascade (Additional file 2). The PKA pathway is involved in second messenger signaling and it is stimulated by upstream cascades including the G protein-coupled receptor pathway (Figure 4). The most significant pathways with thyroid specific functions were the thyroid hormone metabolic and thyronamine/iodothyronamine metabolic pathways.

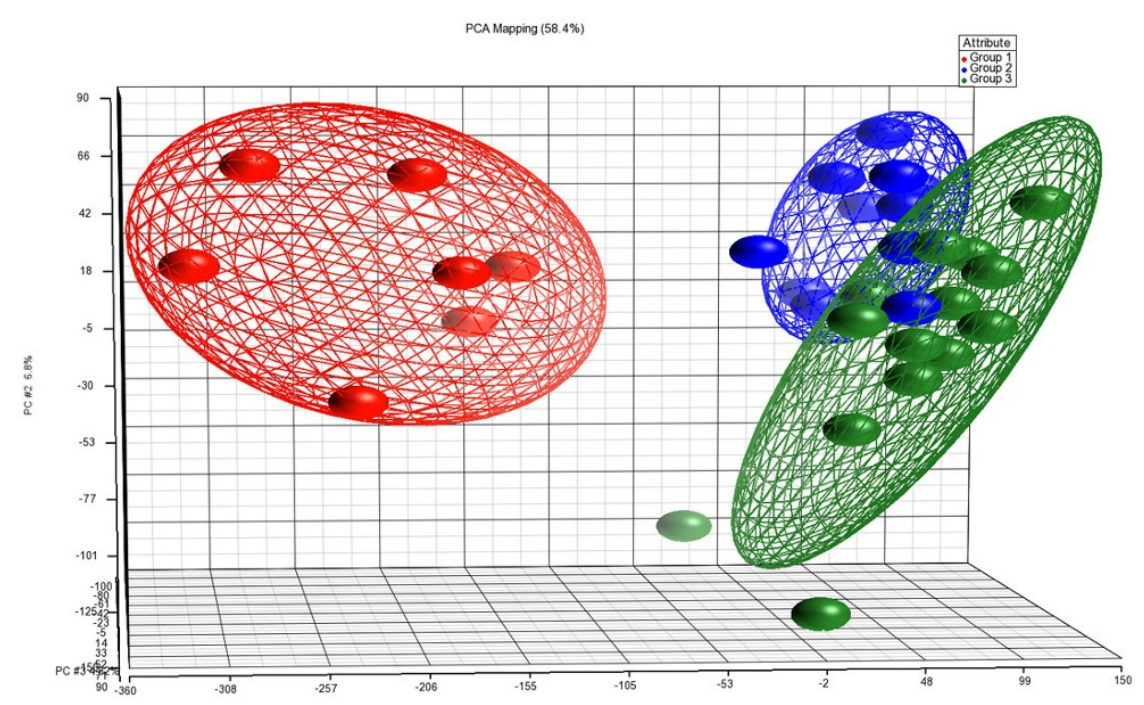

Figure 1 PCA scatter plot wherein each dot represents a sample with a group specific color. Distance between dots is a dimensional measure for the similarity of the respective expression profiles of the samples. Ellipsoids are a measure to visualize distance of relationships between samples of a group. Red, normal thyroid; blue, BRAF ${ }^{\text {wt }}$ PTCs, green, BRAF ${ }^{\text {mut }}$ PTCs. 


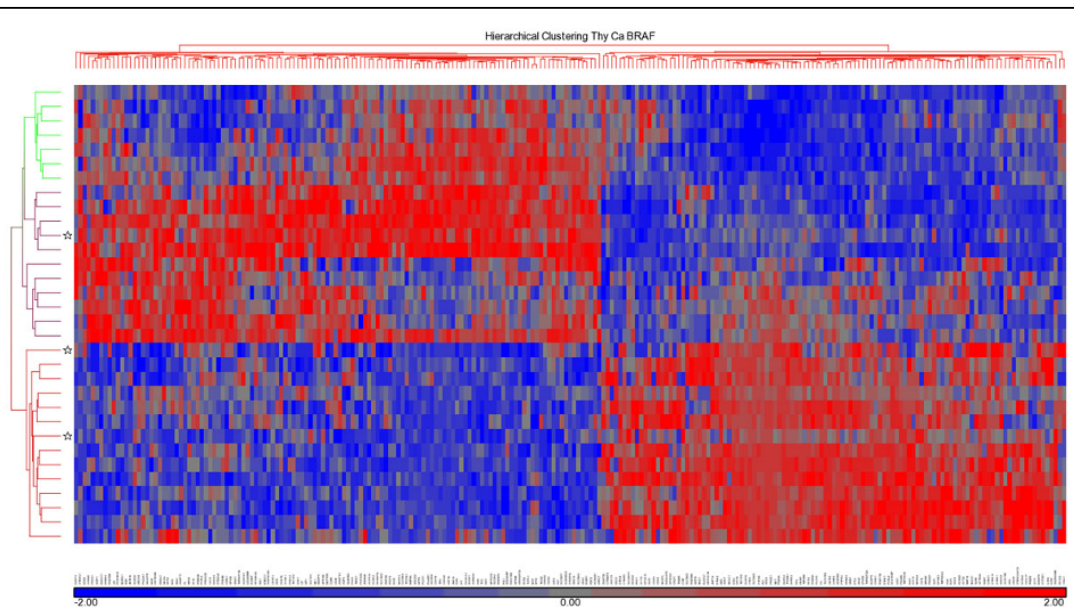

Figure 2 Hierarchical cluster analysis of 237 genes which were differentially expressed between $B R A F^{\text {wt }}$ and $B R A F^{\text {mut }}$ PTCs. Gene expression of TN samples is included in analysis. Color scheme for expression levels: red for comparably higher and blue for comparably lower expression. Color scheme for groups in the left sided branches: green for TN samples, purple for BRAF ${ }^{\text {wt }}$, and red for BRAF ${ }^{\text {mut }}$ PTCs. Stars mark samples from recurrence or local metastasis, and LN metastasis.

Table 2 Differentially expressed genes between $B R A F^{\mathrm{wt}}$ and $B R A F^{\mathrm{mut}}$ PTCs and TN samples

\begin{tabular}{|c|c|c|c|c|c|c|c|}
\hline \multirow[t]{2}{*}{ Gene name } & \multirow[t]{2}{*}{ Gene symbol } & \multicolumn{2}{|c|}{$\begin{array}{l}B R A F^{\mathrm{wt}} \text { PTC vs. } \\
B R A F^{\mathrm{mut}} \text { PTC }\end{array}$} & \multicolumn{2}{|c|}{$\begin{array}{c}B R A F^{\mathrm{wt}} \text { PTC } \\
\text { vs. TN }\end{array}$} & \multicolumn{2}{|c|}{$\begin{array}{c}B R A F^{\text {mut }} \text { PTC } \\
\text { vs. TN }\end{array}$} \\
\hline & & $\mathrm{FC}^{1}$ & $P$ & $\mathrm{FC}^{1}$ & $P$ & $\mathrm{FC}^{1}$ & $P^{2}$ \\
\hline keratin 19 & KRT19 & -4.39 & 1.3E-09 & 2.37 & $2.0 \mathrm{E}-04$ & 10.43 & $8.5 \mathrm{E}-13$ \\
\hline potassium voltage-gated channel, shaker-related subfamily, beta member 1 & KCNAB1 & 7.66 & $6.4 \mathrm{E}-09$ & 3.23 & $5.5 \mathrm{E}-04$ & -2.37 & 5.7E-03 \\
\hline solute carrier family 26, member 4 & SLC26A4 & 7.59 & 4.3E-08 & 2.14 & $2.9 \mathrm{E}-02$ & -3.55 & 4.0E-04 \\
\hline TBC1 domain family, member 2 & TBC1D2 & -2.39 & $4.4 \mathrm{E}-08$ & 2.71 & $1.0 \mathrm{E}-07$ & 6.48 & $3.3 \mathrm{E}-14$ \\
\hline tumor protein D52-like 1 & TPD52L1 & -2.46 & $3.2 \mathrm{E}-07$ & 2.22 & 3.6E-05 & 5.46 & $1.1 \mathrm{E}-11$ \\
\hline TP53 apoptosis effector & PERP & -2.09 & $3.6 \mathrm{E}-07$ & 2.97 & $6.9 \mathrm{E}-09$ & 6.22 & $1.6 \mathrm{E}-14$ \\
\hline Periplakin & PPL & -2.53 & $1.0 \mathrm{E}-06$ & 2.92 & $1.9 \mathrm{E}-06$ & 7.41 & $2.3 \mathrm{E}-12$ \\
\hline growth differentiation factor 15 & GDF15 & -5.08 & $1.5 \mathrm{E}-06$ & 2.41 & $1.1 \mathrm{E}-02$ & 12.23 & $6.8 \mathrm{E}-09$ \\
\hline deltex homolog 4 (Drosophila) & DTX4 & -3.31 & $3.5 \mathrm{E}-06$ & 3.28 & $5.6 \mathrm{E}-05$ & 10.86 & $8.4 \mathrm{E}-11$ \\
\hline death-associated protein kinase 2 & DAPK2 & -2.45 & $1.0 \mathrm{E}-05$ & 2.78 & $2.1 \mathrm{E}-05$ & 6.83 & $7.6 \mathrm{E}-11$ \\
\hline ethanolamine kinase 2 & ETNK2 & -2.51 & $1.9 \mathrm{E}-05$ & 2.02 & $3.0 \mathrm{E}-03$ & 5.07 & $1.3 \mathrm{E}-08$ \\
\hline solute carrier family 34 (sodium phosphate), member 2 & SLC34A2 & -4.75 & $2.2 \mathrm{E}-05$ & 8.86 & $2.2 \mathrm{E}-06$ & 42.09 & $1.9 \mathrm{E}-11$ \\
\hline transmembrane protein 98 & TMEM98 & -2.09 & $2.8 \mathrm{E}-05$ & 2.24 & $9.8 \mathrm{E}-05$ & 4.69 & $6.2 \mathrm{E}-10$ \\
\hline gamma-glutamylcyclotransferase & GGCT & -2.52 & $3.1 \mathrm{E}-05$ & 2.48 & 3.7E-04 & 6.26 & $2.3 \mathrm{E}-09$ \\
\hline purine nucleoside phosphorylase & PNP & -3.55 & $3.4 \mathrm{E}-05$ & 2.48 & $6.6 \mathrm{E}-03$ & 8.82 & 4.7E-08 \\
\hline protein S (alpha) & PROS1 & -2.80 & 3.7E-05 & 5.78 & $1.4 \mathrm{E}-07$ & 16.18 & $2.8 \mathrm{E}-12$ \\
\hline FERM domain containing 4B & FRMD4B & 2.50 & 3.7E-05 & 5.04 & $7.3 \mathrm{E}-08$ & 2.01 & $3.1 \mathrm{E}-03$ \\
\hline mucin 1 , cell surface associated & MUC1 & -2.29 & $5.6 \mathrm{E}-05$ & 2.23 & $6.8 \mathrm{E}-04$ & 5.12 & $6.6 \mathrm{E}-09$ \\
\hline protein tyrosine phosphatase, receptor type, E & PTPRE & -2.22 & $6.0 \mathrm{E}-05$ & 2.45 & $1.3 \mathrm{E}-04$ & 5.43 & $1.5 \mathrm{E}-09$ \\
\hline gamma-aminobutyric acid (GABA) A receptor, beta 2 & GABRB2 & -4.73 & 8.6E-05 & 2.82 & 1.7E-02 & 13.32 & $3.0 \mathrm{E}-07$ \\
\hline metastasis associated in colon cancer 1 & MACC1 & -2.34 & $1.2 \mathrm{E}-04$ & 2.15 & $2.3 \mathrm{E}-03$ & 5.02 & 4.0E-08 \\
\hline Cbp/p300-interacting transactivator, with Glu/Asp-rich carboxy-terminal domain, 1 & CITED1 & -3.58 & $3.4 \mathrm{E}-04$ & 2.56 & $1.8 \mathrm{E}-02$ & 9.17 & $1.1 \mathrm{E}-06$ \\
\hline laminin, beta 3 & LAMB3 & -3.13 & $3.4 \mathrm{E}-04$ & 2.46 & $1.2 \mathrm{E}-02$ & 7.70 & $6.7 \mathrm{E}-07$ \\
\hline syndecan 4 & SDC4 & -2.22 & 4.3E-04 & 4.25 & $1.6 \mathrm{E}-06$ & 9.45 & $1.2 \mathrm{E}-10$ \\
\hline family with sequence similarity 129 , member A & FAM129A & -2.21 & $4.3 \mathrm{E}-04$ & 2.27 & $1.9 \mathrm{E}-03$ & 5.03 & $9.8 \mathrm{E}-08$ \\
\hline
\end{tabular}


Table 2 Differentially expressed genes between $B R A F^{\mathrm{wt}}$ and $B R A F^{\mathrm{mut}}$ PTCs and TN samples (Continued)

\begin{tabular}{|c|c|c|c|c|c|c|c|}
\hline fibronectin 1 & FN1 & -2.60 & $4.9 \mathrm{E}-04$ & 10.31 & $8.2 \mathrm{E}-09$ & 26.78 & $1.5 \mathrm{E}-12$ \\
\hline phosphodiesterase 5A, cGMP-specific & PDE5A & -2.82 & 7.1E-04 & 6.06 & $6.7 \mathrm{E}-06$ & 17.11 & $6.5 \mathrm{E}-10$ \\
\hline dual specificity phosphatase 5 & DUSP5 & -2.11 & $7.9 \mathrm{E}-04$ & 2.16 & $3.1 \mathrm{E}-03$ & 4.57 & $2.8 \mathrm{E}-07$ \\
\hline chitinase 3-like 1 (cartilage glycoprotein-39) & CHI3L1 & -4.45 & $8.5 \mathrm{E}-04$ & 3.50 & $1.4 \mathrm{E}-02$ & 15.59 & $1.8 \mathrm{E}-06$ \\
\hline cathepsin $\mathrm{H}$ & $\mathrm{CTSH}$ & -2.63 & $9.2 \mathrm{E}-04$ & 5.31 & $1.1 \mathrm{E}-05$ & 13.97 & $1.2 \mathrm{E}-09$ \\
\hline trefoil factor 3 (intestinal) & TFF3 & 3.81 & $1.5 \mathrm{E}-05$ & -2.86 & $2.6 \mathrm{E}-02$ & -10.92 & $5.4 \mathrm{E}-06$ \\
\hline to-oncogene (hepatocyte growth fact & MET & -2.27 & $2.7 \mathrm{E}-11$ & 8.93 & $1.3 \mathrm{E}-08$ & 20.25 & 4.6E-12 \\
\hline
\end{tabular}

${ }^{1} \mathrm{FC}$, fold change; -, downregulated in $B R A F^{\mathrm{wt}} \mathrm{PTCs}$ vs. BRAF ${ }^{\text {mut }} \mathrm{PTC}$, downregulated in BRAF ${ }^{\mathrm{wt}} \mathrm{PTCs}$ vs. TN, and downregulated in $B R A F^{\text {mut }}$ PTCs vs. TN; ${ }^{2} \mathrm{p}$-value with FDR $<0.05$ and fold change cutoff $>2$

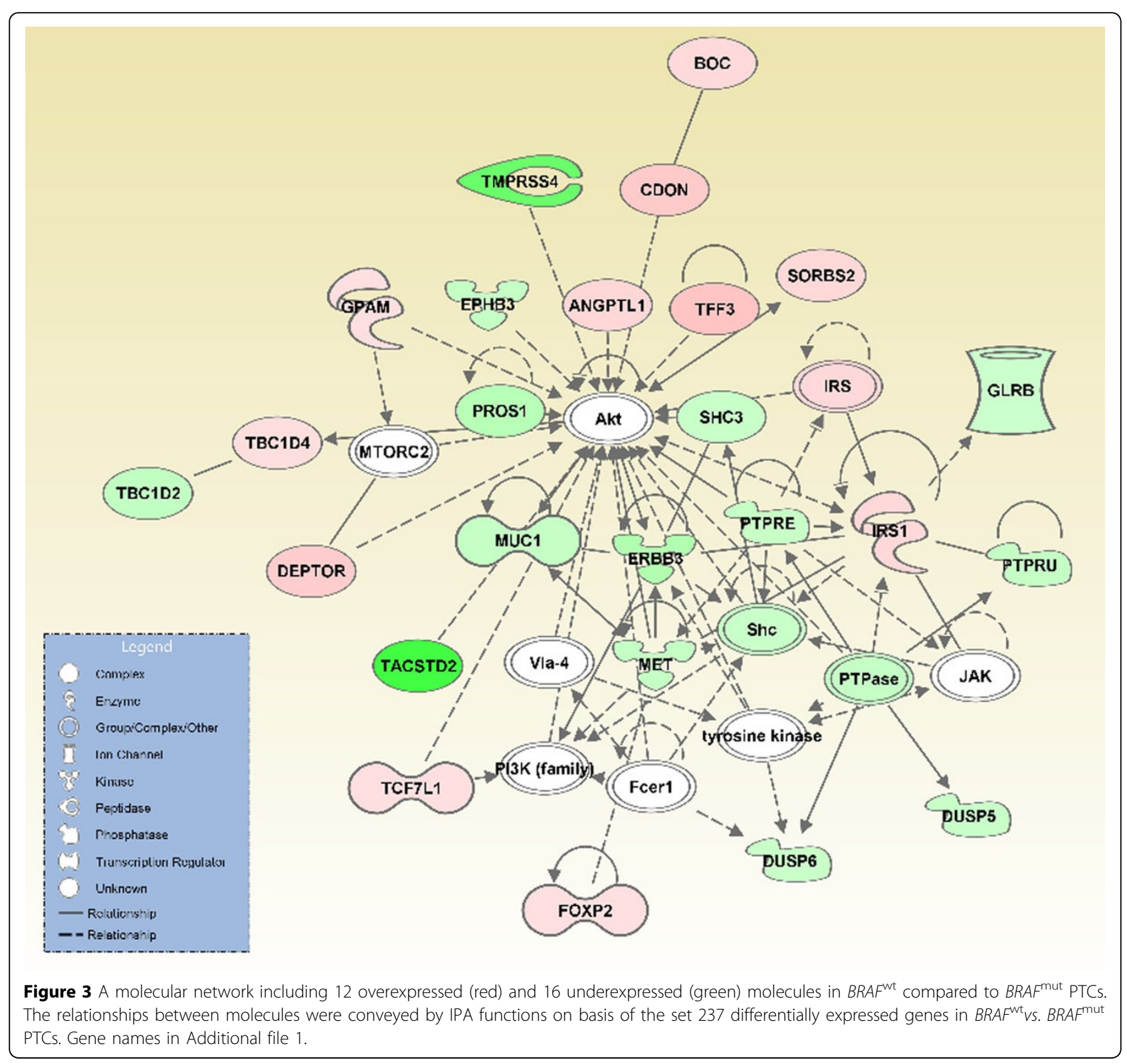




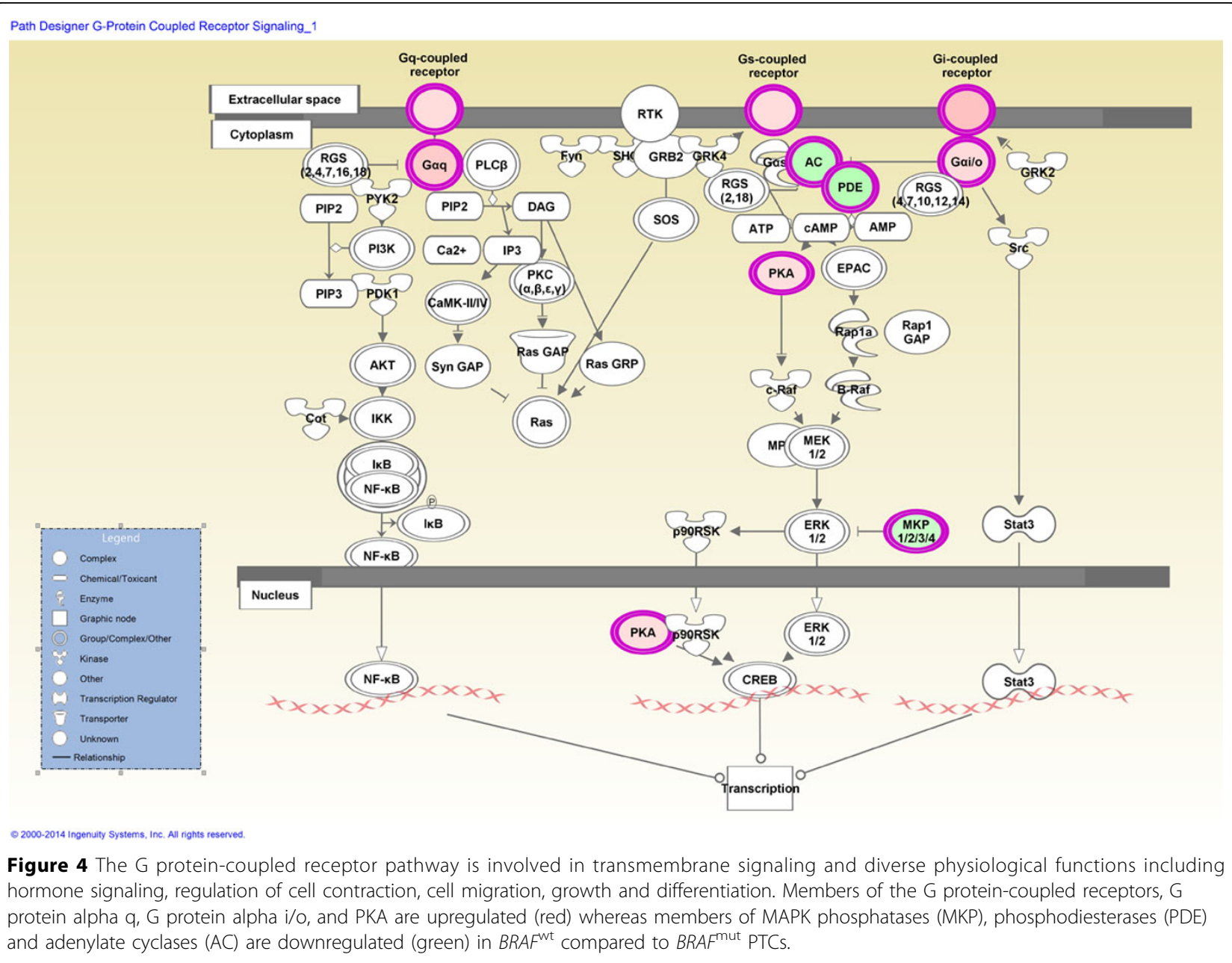

\section{Discussion}

We performed one of the first studies using whole transcript microarrays to compare expression profiles solely in conventional $B R A F^{\mathrm{wt}}$ and $B R A F^{\mathrm{mut}}$ PTCs. Comparison to studies including different histological subtypes of PTCs may result in detecting a lower number of common genes. An expression array study including histological variants of PTC identified, on basis of enhanced stringent threshold criteria, over 80 up- and downregulated genes in the $B R A F^{\text {mut }}$ group in comparison to PTCs with either a RAS mutation or a RET/PTC rearrangement [15] and the 40 most up- and downregulated genes have an overlap of $\sim 40 \%$ to our list of 237 differentially expressed genes.

\section{Selected differentially expressed molecules}

DCSTAMP, also known as TM7SF4, has been previously identified as one of the most overexpressed genes in $B R A F^{\mathrm{mut}}$ PTC compared to $B R A F^{\mathrm{wt}}$ PTC as well in PTC with undetermined mutational status compared to normal thyroid tissue $[15,22,23]$. It has been supposed that
DCSTAMP expression is an immune response related to $B R A F^{\text {mut }}$ tumors [15]. DCSTAMP contains signature motifs owned by the family of transmembrane serine proteases and it exhibits degradation activity against extracellular matrix proteins. One of the functions of the hepatic leukemia factor (HLF) as a transcription factor is to mediate thyroid hormone activation from the thyroid hormone receptor/retinoid X receptor heterodimer to the hypoxiainducible factor (HIF-1alpha) [24]. The function of C19orf33, also known as H2RSP (Hepatocyte growth factor activator inhibitor type 2-related small protein) is virtually unknown. An enhanced expression with higher levels in LN positive tumors has been observed for C19orf33 in colorectal adenocarcinoma cells at the invasive front [25]. The voltage gated channel molecule KCNAB1 exhibits diverse functions including electrolyte transport, and insulin secretion. Downregulation of $K C N A B 1$ expression has been identified in follicular thyroid carcinomas compared to benign follicular adenomas [26]. ELMO1 functionally interacts with dedicator of cytokinesis 1 (DOCK1) that promotes Rac guanine exchange 
factor (GEF) activity for Rac proteins of the Rho GTPases family. GTP-loaded Rac proteins initiate downstream pathways that promote cell elongation, migration, and cytoskeleton remodeling $[27,28]$. The active ELMO1/ DOCK1 complex is anchored via phosphoinositides to the membrane. In our study, the DOCK1 related DOCK5 gene was identified as a 2-fold upregulated molecule in $B R A F^{\mathrm{wt}}$ compared to $B R A F^{\text {mut }}$ PTCs. The leucine-rich repeat and immunoglobulin-like domain-containing nogo receptorinteracting protein 2 (LINGO2) encodes a single-pass type I membrane protein that is primarily expressed during development in cells adjunct to the epithelial lining of the olfactory pit and in adult brain [29]. In our study, LINGO2 was downregulated in $B R A F^{\mathrm{wt}}$ PTCs and even more in $B R A F^{\text {mut }}$ PTCs compared to TN samples which may imply a tumor suppressor function for this molecule. Higher expression levels of the ERK1/2-specific cytoplasmic dual specificity phosphatase 6 (DUSP6) in comparison to benign and normal thyroid cells has been previously associated with PTC, especially with advanced thyroid carcinomas [30,31]. In our study, DUSP6 was 2.1 times higher expressed in $B R A F^{\text {mut }}$ than in $B R A F^{\mathrm{wt}}$ PTCs assuming that the ERK $1 / 2$ related pathway is frequently more utilized in the $B R A F^{\text {mut }}$ group. MET overexpression in thyroid cancer has been identified in a number of studies and this molecule was 2.3-fold higher expressed in our study in $B R A F$ mut compared to $B R A F^{\mathrm{wt}}$ PTCs which is in accordance with another survey [15] (Table 2).

\section{Second messenger molecules}

ITPR1 is an intracellular receptor for inositol 1,4,5-trisphosphate (IP3) and implicated in the thyroid hormone synthesis pathway. The receptor mediates calcium release from the endoplasmic reticulum upon stimulation by IP3. Downregulation of ITPR1 has been demonstrated in thyroid cancer in comparison to non-malignant thyroid tissue in a number of studies [32-35]. Among the members of the phospholipase C (PLC) family, PLCH1 was upregulated in $B R A F^{\mathrm{wt}}$ PTCs whereas PLCD3 was downregulated. PLC molecules hydrolyze phosphatidylinositol 4,5-bisphosphate to generate the second messengers diacylglycerol and IP3.

\section{Thyroid hormone pathway molecules}

$L A D 1$ has been identified as an overexpressed gene in $B R A F^{\text {mut }}$ thyroid carcinomas compared to those with a $\mathrm{RET} / \mathrm{PTC}$ rearrangement [18]. Lad1 expression is regulated by the glucocorticoid receptor (GR) and requires for induction the GR coactivators thyroid hormone receptor associated protein 220 (MED1) and the thyroid hormone receptor associated protein 170 (MED14) [36]. Downregulation of TPO has been considered in a number of studies comparing thyroid carcinomas with benign thyroid tumors or normal thyroid samples $[32,33,37,38]$. However, downregulation of TPO and the sodium iodine symporter genes as been previously associated with $B R A F^{\text {mut }}$ PTCs in comparison to PTCs with a RET/PTC rearrangement [39]. This is in line with observations that $B R A F^{\text {mut }}$ tumors are refractory for radioactive iodine ablation due to downregulation of thyroid hormone biosynthesis pathways [40]. $T P O$ was in our study 13 -fold downregulated in $B R A F^{\text {mut }}$ compared to $B R A F^{\mathrm{wt}}$ PTCs. In addition, other genes involved in thyroid hormone biosynthesis pathway including the solute carrier family-5 member-8 (SLC5A8), solute carrier family 26 (anion exchanger), member 4 (SLC26A4), deiodinase, iodothyronine, type I (DIO1) and deiodinase, iodothyronine, type II (DIO2) were downregulated in our set of $B R A F^{\text {mut }}$ PTCs. Other members of the SLC family that were downregulated in $B R A F^{\text {mut }}$ PTCs were $S L C 1 A 3$, $S L C 4 A 4$, SLC16A2, and SLC26A7 whereas SLC22A31, $S L C 30 A 2$, and SLC34A2 were downregulated in $B R A F^{\mathrm{wt}}$ PTCs.

\section{$E R B B 3$ and ERRB4 genes}

Two of the four structurally related receptor tyrosine kinases ErbB, namely $E R B B 3$ and $E R B B 4$, were differentially expressed in the two PTC groups, i.e. $E R B B 3$ was downregulated and ERBB4 upregulated in $B R A F^{\mathrm{wt}}$ PTCs (Additional file 1). Of notice, ERBB4 was also lower expressed in BRAF ${ }^{\text {mut }}$ PTCs compared to TN samples $(p=0.0035)$ (data not shown). Oncogenic functions of ERBB3 and ERBB4, which can form heterodimers and signal through the PI3K/AKT signaling pathway have not been elucidated yet in detail in relation to the $B R A F$ mutational status in thyroid cancer [41-43]; however, decreased expression of ERBB4 in PTC vs. normal thyroid tissue has been demonstrated in a RT-PCR study whereas $E R B B 2$ and $E R B B 3$ expression was shown to be increased [44]. On the protein level, a tissue microarray study in proliferative thyroid lesions found a correlation of ERBB3 expression with LN metastasis whereas ERBB4 expression correlated with lower tumor stage [45]. A possible link of $E R B B 3$ to apoptosis can be deduced from a functional in vivo study wherein deletion of $E R B B 3$ in mouse intestinal epithelium induced tumor-specific cell death [46].

\section{MicroRNAs}

The most significantly downregulated microRNA in $B R A F^{\mathrm{wt}}$ compared to $B R A F^{\mathrm{mut}}$ PTCs was mir492 and the most upregulated one was mir32. Overexpression of mir492 has been previously linked to progressive hepatoblastoma and tumorigenesis of retinoblastoma $[47,48]$. Of notice, mir492 is processed from the KRT19 gene [47] and both are higher expressed. A possible target for miR492 is the 3'UTR of KRT19 [49] which is 4.4-fold higher expressed in $B R A F^{\text {mut }}$ PTCs compared to $B R A F^{\mathrm{wt}}$ PTCs suggesting an accumulation of the KRT19 mRNA. Another possible target of miR492 is the thyroid hormone receptor-associated protein 3 (THRAP3) mRNA that harbors two predicted target 
sites for miR492 [49] and that is significantly downregulated in our case series by approximately 3 -fold in both, $B R A F^{\mathrm{wt}}$ and $B R A F^{\mathrm{mut}}$ PTCs compared to TN samples. Upregulation of mir32 in thyroid cancer $v s$. benign thyroid tumors has been detected in a microarray study; however functional implication of this microRNA in PTC is not known yet [50].

In summary, our microarray expression study provides a detailed overview of differentially expressed genes, networks, and pathways between $B R A F^{\mathrm{wt}}$ and $B R A F^{\mathrm{mut}}$ PTCs that gain interest for basic molecular genetics and translational studies in PTCs.

\section{Additional material}

Additional file 1: The 237 most differentially expressed genes in
$B R A F^{\text {wt }}$ vs. BRAF ${ }^{\text {mut }}$ papillary thyroid carcinomas.
Additional file 2: The canonical PKA pathway is a second
messenger cascade and involved in diverse functions as growth,
development, metabolism, DNA replication/recombination, DNA
repair and cellular organization. A number of molecules including
members of PKA, ryanodine receptors (RYR), inositol trisphosphate
receptors (IP3R), and lymphoid enhancing factors/T-cell factors
(TCF/LEF) are upregulated (red) and number of molecules including
members of phospholipases C (PLC), 14-3-3 proteins, and protein
tyrosine phosphatases (PTP) are downregulated (green) in $B R A F^{\mathrm{wt}}$
compared to $B R A F^{\text {mut }}$ PTCs.

List of abbreviations

$B R A F^{\text {wt }}$ : BRAF wild type; BRAF $F^{\text {mut }}$ : BRAF mutant; FVPTC: follicular variant of PTC; LN: lymph node; PTC: papillary thyroid carcinoma; TN: normal thyroid.

\section{Competing interests}

The authors declare that they have no competing interests.

\section{Authors' contributions}

$\mathrm{JM}, \mathrm{EH}, \mathrm{MG}$, and $\mathrm{MHQ}$ made substantial contributions to conception and design of the study. RA, AA, and MA processed expression arrays, performed BRAF mutational analysis, and were involved in data interpretation. KG, FM, and $\mathrm{OAH}$ were responsible for surgeries, oversight of clinical databases and contributed to the conception and design of the study. JM performed histological examinations. SK and HJS performed data analysis. HJS had general oversight of the study. HJS, JM, and MHQ interpreted data and drafted the manuscript. All authors read and approved the final manuscript.

\section{Acknowledgements}

We thank Nadia Bagtian, Ohoud Subhi, and Shireen Hussain for excellent technical assistance. This study was supported by King Abdulaziz City for Science and Technology (KACST) grants 13-BIO2289-03 and 09-BIO820-03.

\section{Declarations}

Publication charges for this article have been funded by the Center of Excellence in Genomic Medicine Research (CEGMR), King Abdulaziz University, Jeddah, Kingdom of Saudi Arabia.

This article has been published as part of BMC Genomics Volume 16 Supplement 1, 2015: Selected articles from the 2nd International Genomic Medical Conference (IGMC 2013): Genomics. The full contents of the supplement are available online at http://www.biomedcentral.com/ bmcgenomics/supplements/16/S1

\section{Authors' details}

${ }^{1}$ Center of Excellence in Genomic Medicine Research, King Abdulaziz University, Jeddah, Saudi Arabia. ${ }^{2}$ KACST Technology Innovation Center in Personalized Medicine, King Abdulaziz University, Jeddah, Saudi Arabia. ${ }^{3}$ Department of Biochemistry, King Abdulaziz University, Jeddah, Saudi
Arabia. ${ }^{4}$ Department of Surgery, Faculty of Medicine, King Abdulaziz University, Jeddah, Saudi Arabia. ${ }^{5}$ Department of Surgery, King Faisal Specialist Hospital and Research Center, Jeddah, Saudi Arabia. ${ }^{6}$ Department of Pathology, Faculty of Medicine, King Abdulaziz University, Jeddah, Saudi Arabia. ${ }^{7}$ Department of Pathology and Laboratory Medicine, King Faisal Specialist Hospital and Research Center, Jeddah, Saudi Arabia.

Published: 15 January 2015

\section{References}

1. Pellegriti G, Frasca F, Regalbuto C, Squatrito S, Vigneri R: Worldwide increasing incidence of thyroid cancer: update on epidemiology and risk factors. Journal of cancer epidemiology 2013, 2013(965212).

2. Hussain F, lqbal S, Mehmood A, Bazarbashi S, Elhassan T, Chaudhri N: Incidence of thyroid cancer in the Kingdom of Saudi Arabia, 2000-2010. Hematol Oncol Stem Cell Ther 2013, 6(2):58-64.

3. Yu XM, Schneider DF, Leverson G, Chen H, Sippel RS: Follicular Variant of Papillary Thyroid Carcinoma is a Unique Clinical Entity: A PopulationBased Study of 10,740 Cases. Thyroid : official journal of the American Thyroid Association 2013, 23(10):1263-1268.

4. Roman S, Sosa JA: Aggressive variants of papillary thyroid cancer. Current opinion in oncology 2013, 25:33-38.

5. Schulten HJ, Salama S, Al-Mansouri Z, Alotibi R, Al-Ghamdi K, AlHamour OA, Sayadi H, Al-Aradati H, Al-Johari A, Huwait E, et al: BRAF mutations in thyroid tumors from an ethnically diverse group. Hereditary cancer in clinical practice 2012, 10:10.

6. El-Osta H, Falchook G, Tsimberidou A, Hong D, Naing A, Kim K, Wen S, Janku F, Kurzrock R: BRAF mutations in advanced cancers: clinical characteristics and outcomes. PloS one 2011, 6:e25806.

7. Lee JH, Lee ES, Kim YS: Clinicopathologic significance of BRAF V600E mutation in papillary carcinomas of the thyroid: a meta-analysis. Cancer 2007, 110:38-46.

8. Tufano RP, Teixeira GV, Bishop J, Carson KA, Xing M: BRAF mutation in papillary thyroid cancer and its value in tailoring initial treatment: a systematic review and meta-analysis. Medicine 2012, 91:274-286.

9. Xing M, Alzahrani AS, Carson KA, Viola D, Elisei R, Bendlova B, Yip L, Mian C, Vianello F, Tuttle RM, et al: Association between BRAF V600E mutation and mortality in patients with papillary thyroid cancer. JAMA : the journal of the American Medical Association 2013, 309:1493-1501.

10. Kim TH, Park YJ, Lim JA, Ahn HY, Lee EK, Lee YJ, Kim KW, Hahn SK, Youn YK, $\mathrm{Kim} \mathrm{KH}$, et al: The association of the BRAF(V600E) mutation with prognostic factors and poor clinical outcome in papillary thyroid cancer: a meta-analysis. Cancer 2012, 118:1764-1773.

11. Morris V, Kopetz S: BRAF inhibitors in clinical oncology. F1000prime reports 2013, 5:11.

12. Patel KN, Singh B: Genetic considerations in thyroid cancer. Cancer control: journal of the Moffitt Cancer Center 2006, 13(2):111-118.

13. Schulten HJ, Salama S, Al-Ahmadi A, Al-Mansouri Z, Mirza Z, Al-Ghamdi K, Al-Hamour OA, Huwait E, Gari M, Al-Qahtani MH, Al-Maghrabi J: Comprehensive Survey of HRAS, KRAS, and NRAS Mutations in Proliferative Thyroid Lesions from An Ethnically Diverse Population. Anticancer Res 2013, 33:4779-4784.

14. Ishizaka Y, Kobayashi S, Ushijima T, Hirohashi S, Sugimura T, Nagao M: Detection of retTPC/PTC transcripts in thyroid adenomas and adenomatous goiter by an RT-PCR method. Oncogene 1991, 6:1667-1672.

15. Giordano TJ, Kuick R, Thomas DG, Misek DE, Vinco M, Sanders D, Zhu Z, Ciampi R, Roh M, Shedden K, et al: Molecular classification of papillary thyroid carcinoma: distinct BRAF, RAS, and RET/PTC mutation-specific gene expression profiles discovered by DNA microarray analysis. Oncogene 2005, 24:6646-6656.

16. Durand S, Ferraro-Peyret C, Joufre M, Chave A, Borson-Chazot F, SelmiRuby S, Rousset B: Molecular characteristics of papillary thyroid carcinomas without BRAF mutation or RET/PTC rearrangement: relationship with clinico-pathological features. Endocr Relat Cancer 2009, 16:467-481.

17. Frattini $M$, Ferrario $C$, Bressan $P$, Balestra $D$, De Cecco $L$, Mondellini $P$, Bongarzone I, Collini P, Gariboldi M, Pilotti S, et al: Alternative mutations of BRAF, RET and NTRK1 are associated with similar but distinct gene expression patterns in papillary thyroid cancer. Oncogene 2004, 23:7436-7440. 
18. Rusinek D, Szpak-Ulczok S, Jarzab B: Gene expression profile of human thyroid cancer in relation to its mutational status. Journal of molecular endocrinology 2011, 47:R91-103.

19. Thyroid. In AJCC Cancer Staging Manual. New York: Springer;Edge SB BD, Compton CC, Fritz AG, Greene FL, Trotti A 2010:87-96.

20. DeLellis RA, Williams ED: Thyroid and parathyroid tumors. In Pathology and genetics of tumours of endocrine organs (IARC WHO classification of tumours). Lyons: IARC Press;DeLellis RA, Lloyd RV, Heitz PU, Eng C 2004:51-56.

21. Brazma A, Hingamp P, Quackenbush J, Sherlock G, Spellman P, Stoeckert C, Aach J, Ansorge W, Ball CA, Causton HC, et al: Minimum information about a microarray experiment (MIAME)-toward standards for microarray data. Nature genetics 2001, 29:365-371.

22. Kim HS, Kim do H, Kim JY, Jeoung NH, Lee IK, Bong JG, Jung ED: Microarray analysis of papillary thyroid cancers in Korean. The Korean journal of internal medicine 2010, 25:399-407.

23. Siraj AK, Bavi P, Abubaker J, Jehan Z, Sultana M, Al-Dayel F, Al-Nuaim A, Alzahrani A, Ahmed M, Al-Sanea O, et al: Genome-wide expression analysis of Middle Eastern papillary thyroid cancer reveals c-MET as a novel target for cancer therapy. J Pathol 2007, 213:190-199.

24. Otto T, Fandrey J: Thyroid hormone induces hypoxia-inducible factor 1alpha gene expression through thyroid hormone receptor beta/retinoid $\mathrm{x}$ receptor alpha-dependent activation of hepatic leukemia factor. Endocrinology 2008, 149:2241-2250.

25. Uchiyama S, Itoh H, Naganuma S, Nagaike K, Fukushima T, Tanaka H, Hamasuna R, Chijiwa K, Kataoka H: Enhanced expression of hepatocyte growth factor activator inhibitor type 2-related small peptide at the invasive front of colon cancers. Gut 2007, 56:215-226.

26. Pfeifer A, Wojtas B, Oczko-Wojciechowska M, Kukulska A, Czarniecka A Eszlinger M, Musholt T, Stokowy T, Swierniak M, Stobiecka E, et al: Molecular differential diagnosis of follicular thyroid carcinoma and adenoma based on gene expression profiling by using formalin-fixed paraffin-embedded tissues. BMC medical genomics 2013, 6:38.

27. Hanawa-Suetsugu K, Kukimoto-Niino M, Mishima-Tsumagari C, Akasaka R, Ohsawa N, Sekine S, Ito T, Tochio N, Koshiba S, Kigawa T, et al: Structural basis for mutual relief of the Rac guanine nucleotide exchange factor DOCK2 and its partner ELMO1 from their autoinhibited forms. Proceedings of the National Academy of Sciences of the United States of America 2012, 109:3305-3310.

28. Patel M, Pelletier A, Cote JF: Opening up on ELMO regulation: New insights into the control of Rac signaling by the DOCK180/ELMO complex. Small GTPases 2011, 2:268-275.

29. Haines BP, Rigby PW: Expression of the Lingo/LERN gene family during mouse embryogenesis. Gene Expr Patterns 2008, 8:79-86.

30. Lee JU, Huang S, Lee MH, Lee SE, Ryu MJ, Kim SJ, Kim YK, Kim SY, Joung $\mathrm{KH}$, Kim JM, et al: Dual specificity phosphatase 6 as a predictor of invasiveness in papillary thyroid cancer. European journal of endocrinology / European Federation of Endocrine Societies 2012, 167:93-101.

31. Degl'Innocenti D, Romeo P, Tarantino E, Sensi M, Cassinelli G, Catalano V, Lanzi C, Perrone F, Pilotti S, Seregni E, et al: DUSP6/MKP3 is overexpressed in papillary and poorly differentiated thyroid carcinoma and contributes to neoplastic properties of thyroid cancer cells. Endocr Relat Cancer 2013, 20:23-37.

32. Griffith $\mathrm{OL}$, Melck A, Jones SJ, Wiseman SM: Meta-analysis and metareview of thyroid cancer gene expression profiling studies identifies important diagnostic biomarkers. J Clin Oncol 2006, 24:5043-5051.

33. Huang Y, Prasad M, Lemon WJ, Hampel H, Wright FA, Kornacker K, LiVolsi V, Frankel W, Kloos RT, Eng C, et al: Gene expression in papillary thyroid carcinoma reveals highly consistent profiles. Proceedings of the National Academy of Sciences of the United States of America 2001, 98:15044-15049.

34. Finley DJ, Zhu B, Barden CB, Fahey TJ 3rd: Discrimination of benign and malignant thyroid nodules by molecular profiling. Ann Surg 2004, 240:425-436, discussion 436-427.

35. Barden CB, Shister KW, Zhu B, Guiter G, Greenblatt DY, Zeiger MA, Fahey TJ 3rd: Classification of follicular thyroid tumors by molecular signature: results of gene profiling. Clinical cancer research : an official journal of the American Association for Cancer Research 2003, 9:1792-1800.

36. Wang Z, Chen W, Kono E, Dang T, Garabedian MJ: Modulation of glucocorticoid receptor phosphorylation and transcriptional activity by a C-terminal-associated protein phosphatase. Molecular endocrinology 2007, 21:625-634.
37. Prasad NB, Somervell $H$, Tufano RP, Dackiw AP, Marohn MR, Califano JA, Wang Y, Westra WH, Clark DP, Umbricht CB, et al: Identification of genes differentially expressed in benign versus malignant thyroid tumors. Clinical cancer research : an official journal of the American Association for Cancer Research 2008, 14:3327-3337.

38. Tanaka T, Umeki K, Yamamoto I, Sugiyama S, Noguchi S, Ohtaki S: Immunohistochemical loss of thyroid peroxidase in papillary thyroid carcinoma: strong suppression of peroxidase gene expression. J Pathol 1996, 179(1):89-94

39. Romei C, Ciampi R, Faviana P, Agate L, Molinaro E, Bottici V, Basolo F, Miccoli P, Pacini F, Pinchera A, Elisei R: BRAFV600E mutation, but not RET/ PTC rearrangements, is correlated with a lower expression of both thyroperoxidase and sodium iodide symporter genes in papillary thyroid cancer. Endocr Relat Cancer 2008, 15:511-520.

40. Xing M: Molecular pathogenesis and mechanisms of thyroid cancer. Nature reviews Cancer 2013, 13:184-199.

41. Kondo T, Ezzat S, Asa SL: Pathogenetic mechanisms in thyroid follicularcell neoplasia. Nature reviews Cancer 2006, 6:292-306.

42. Mincione G, Di Marcantonio MC, Tarantelli C, D'Inzeo S, Nicolussi A, Nardi F, Donini CF, Coppa A: EGF and TGF-beta1 Effects on Thyroid Function. Journal of thyroid research 2011, 2013(431718).

43. Montero-Conde C, Ruiz-Llorente S, Dominguez JM, Knauf JA, Viale A, Sherman EJ, Ryder M, Ghossein RA, Rosen N, Fagin JA: Relief of feedback inhibition of HER3 transcription by RAF and MEK inhibitors attenuates their antitumor effects in BRAF-mutant thyroid carcinomas. Cancer discovery 2013, 3:520-533.

44. Kato S, Kobayashi T, Yamada K, Nishii K, Sawada H, Ishiguro H, Itoh M, Funahashi $H$, Nagasaka A: Expression of erbB receptors mRNA in thyroid tissues. Biochim Biophys Acta 2004, 1673:194-200.

45. Wiseman SM, Griffith OL, Melck A, Masoudi H, Gown A, Nabi IR, Jones SJ: Evaluation of type 1 growth factor receptor family expression in benign and malignant thyroid lesions. American journal of surgery 2008, 195:667-673, discussion 673.

46. Lee D, Yu M, Lee E, Kim H, Yang Y, Kim K, Pannicia C, Kurie JM, Threadgill DW: Tumor-specific apoptosis caused by deletion of the ERBB3 pseudo-kinase in mouse intestinal epithelium. The Journal of clinical investigation 2009, 119:2702-2713.

47. von Frowein J, Pagel P, Kappler R, von Schweinitz D, Roscher A, Schmid I: MicroRNA-492 is processed from the keratin 19 gene and up-regulated in metastatic hepatoblastoma. Hepatology 2011, 53:833-842.

48. Zhao JJ, Yang J, Lin J, Yao N, Zhu Y, Zheng J, Xu J, Cheng JQ, Lin JY, Ma X: Identification of miRNAs associated with tumorigenesis of retinoblastoma by miRNA microarray analysis. Child's nervous system : ChNS : official journal of the International Society for Pediatric Neurosurgery 2009, 25:13-20.

49. Hsu SD, Chu CH, Tsou AP, Chen SJ, Chen HC, Hsu PW, Wong YH, Chen YH, Chen GH, Huang HD: miRNAMap 2.0: genomic maps of microRNAs in metazoan genomes. Nucleic acids research 2008, 36:D165-169.

50. Kitano M, Rahbari R, Patterson EE, Xiong Y, Prasad NB, Wang Y, Zeiger MA, Kebebew E: Expression profiling of difficult-to-diagnose thyroid histologic subtypes shows distinct expression profiles and identify candidate diagnostic microRNAs. Annals of surgical oncology 2011, 18:3443-3452.

doi:10.1186/1471-2164-16-S1-S6

Cite this article as: Schulten et al.: Effect of BRAF mutational status on expression profiles in conventional papillary thyroid carcinomas. BMC Genomics 2015 16(Suppl 1):S6. 